Article

\title{
Testing the Accuracy of Pont's Index in Diagnosing Maxillary Transverse Discrepancy as Compared to the University of Pennsylvania CBCT Analysis
}

\author{
Dana Feştilă ${ }^{1}\left(\mathbb{D}\right.$, Aurelia Magdalena Enache ${ }^{2, *}$, Evelyn Beatrix Nagy ${ }^{3, * \mathbb{D}}$, Mihaela Hedeşiu ${ }^{1}$ and Mircea Ghergie $^{1}$ \\ 1 Department of Orthodontics and Dentofacial Orthopedics, Faculty of Dental Medicine, University of \\ Medicine and Pharmacy “Iuliu Haţieganu”, 400349 Cluj-Napoca, Romania; dana.festila@gmail.com (D.F.); \\ mhedesiu@umfcluj.ro (M.H.); mirceaghergie@yahoo.com (M.G.) \\ 2 Department of Orthodontics and Dentofacial Orthopedics, Faculty of Dental Medicine, \\ "C. Davilla" University of Medicine and Pharmacy, 020021 Bucharest, Romania \\ 3 B-Line Dent, Str. Observatorului nr. 7 ap. 35, 400500 Cluj-Napoca, Romania \\ * Correspondence: enache_magdalena@yahoo.com (A.M.E.); nagy.evelyn.beatrix@gmail.com (E.B.N.)
}

Citation: Feştilă, D.; Enache, A.M.; Nagy, E.B.; Hedeşiu, M.; Ghergie, M. Testing the Accuracy of Pont's Index in Diagnosing Maxillary Transverse Discrepancy as Compared to the University of Pennsylvania CBCT Analysis. Dent. J. 2022, 10, 23. https://doi.org/10.3390/dj10020023

Academic Editor: Andrea Scribante

Received: 20 November 2021

Accepted: 29 January 2022

Published: 4 February 2022

Publisher's Note: MDPI stays neutral with regard to jurisdictional claims in published maps and institutional affiliations.

Copyright: (C) 2022 by the authors. Licensee MDPI, Basel, Switzerland. This article is an open access article distributed under the terms and conditions of the Creative Commons Attribution (CC BY) license (https:// creativecommons.org/licenses/by/ $4.0 /)$.

\begin{abstract}
Introduction: Assessment of maxillary transverse discrepancy requires an accurate tool in order to implement the appropriate treatment plan. Aim: To evaluate the accuracy of Pont's Index in confirming a transverse maxillary deficiency by comparing its results with the corresponding results yielded by the University of Pennsylvania CBCT analysis. Material and methods: The study was performed on dental casts and CBCT's of 60 randomly selected patients by adopting a cluster sampling method. The results of Pont's Index and University of Pennsylvania CBCT analysis were analyzed through McNemar's test using Excel Data Analysis, and the accuracy indicators for Pont's Index were computed using MedCalc Ltd. Results: Mc Nemar's test revealed a $p$-value of 0.85 . The accuracy indicators of Pont's Index were: sensitivity: 69\%; specificity: $16.6 \%$; positive predictive value: $65 \%$; negative predictive value: $18.75 \%$; positive likelihood ratio: 0.83 ; negative likelihood ratio: 1.86 ; and accuracy: $53.28 \%$. Conclusion: Due to the fact that CBCT is not used on a daily basis and Pont's Index has a relatively high sensitivity (69\%) making it suitable to detect patients with a narrow maxilla, assessment of the maxillary deficiency on CBCT can be recommended for cases were the midpalatal suture maturation should be evaluated.
\end{abstract}

Keywords: orthodontics; maxilla; transverse discrepancy; CBCT; diagnosis

\section{Introduction}

It is widely known that maxillary transverse discrepancy (MTD) is a common trait of malocclusions; hence its accurate evaluation for appropriate treatment is mandatory to reduce the side effects of different modalities of maxillary expansion and to obtain good dental and skeletal stability and a balanced smile [1-3]. Besides clinical evaluation, the diagnosis of MTD can be made lighter and more accurate by using dental casts, X-rays examinations, and 3D imaging [1-4]. As the diagnosis of MTD is often challenging, one should use at least two of the previously mentioned methods. As it is known, the roll and yaw of the jaws and dentition affect the dentofacial transverse relationship; hence it is of great importance to distinguish between skeletal and dental maxillary deficiency [5]. Besides dental compensation of a skeletal MTD by the buccolingual inclination of the posterior teeth, the anterioposterior component of malocclusion can classify the MTD in real or relative because a class II relationship can mask an MTD, whereas a class III can accentuate it [6]. After having performed clinical examination of the occlusion in the transverse plane and of the palatal vault shape and appearance, since the most frequent clinical signs of MTD are uni-or bilateral posterior crossbite, crowding, V-shape, and narrow palate, dental casts examination is the first step to confirm the MTD by measuring Pont's 
and McNamara Index [7,8]. However, Pont's Index has some limitations determined by abnormal variations of the mesiodistal width of the incisors, mesiodistal position, and buccolingual inclination of the premolars and molars (as a compensation of the maxillary skeletal deficiency).

2D X-ray examination (posteroanterior cephalogram) was considered a more accurate method to assess MTD, but it also has limitations regarding the accuracy of landmark placement and expertise of the practitioner to determine the landmarks [9].

New 3D imaging is a feasible diagnostic tool in patient assessment, as digital models and CT scans have considerably improved the diagnostic method for assessing dental and skeletal maxillary deficiency [10]. Novel technology and the article by Tamburrino et al. (2010) opened a new direction of research towards the contribution of cone-beam computed tomography $(\mathrm{CBCT})$ in the evaluation and diagnosis of the yet scarcely researched transverse dimension of the maxilla [1,4]. To date, the measurement of the transverse discrepancy of the jaws is rarely among the case types in which CBCT could be justified for optimal treatment outcomes [4]. Exploring this area could bring new enlightenments about this perspective.

Although CBCT entered dentistry in 1998, scientific evidence of improving treatment planning and treatment outcomes in orthodontics has emerged only recently [4]. 3D technology is undergoing rapid evolution, yet several aspects, such as indications for CBCT imaging and protocols regarding diagnosis, need further research [2,4]. Nevertheless, the novel technology already allowed orthodontists to obtain measurements without distortions, thus enabling research on the diagnosis of maxillary narrowing using CBCT imaging by calculating the difference in width between the maxilla (Mx-Mx) and the mandible (WALA-WALA) [1]. Two gold standards were established, these being the University of Pennsylvania CBCT analysis (UPCBCT analysis) and center of alveolar crest (CAC) technique [11,12].

One of the benefits of CBCT lies in its volumetric information that overcomes the limitations of 2D imaging that has distortion, magnification, incorrect head position, and superimposition [4]. The advantage of the cone-beam computer tomography proposed by the UPCBCT analysis emerges from the ease of landmark identification, which no longer enforces the landmark selection for measuring the widths of the jaws [1]. Another considerable benefit of CBCT to diagnose MTD is the use of differential data to analyze the lower arch expansion. Since RME determines a slight buccal inclination and a slight increase in the intra-arch width between mandibular posterior teeth, with no difference between tooth-borne or bone-borne appliance, one has to consider it for the treatment plan $[13,14]$.

Pont's Index (PI) assesses MTD by comparing the ideal inter-premolar (IP) and intermolar (IM) distances to the calculated IP and IM. The advantages of PI are the lack of radiation, ease of use, and low cost. Although Pont's Index (PI) is widely used, further studies on various ethnic groups are needed to take into consideration their craniofacial parameters [15].

The purpose of the current study was to evaluate the accuracy of PI as a diagnostic method in confirming MTD by comparing the obtained results with the corresponding results yielded by the UPCBCT analysis, thus assessing the importance and the usefulness of the two tools in the diagnostic process.

The main objective was to test a link between the test results obtained by PI and the presence or absence of MTD as indicated by the gold standard, the UPCBCT analysis.

The second objective was to quantify the importance of the correlation by computing accuracy indicators.

The following hypotheses were considered:

$\mathrm{H}_{0}$ : The difference between the results of PI and UPCBCT analysis in the accuracy of diagnosing MTD is not statistically significant. 
$H_{1}$ : The difference between the results of PI and UPCBCT analysis in the accuracy of diagnosing MTD is statistically significant, with PI being less accurate in diagnosing a transverse maxillary deficiency than the UPCBCT analysis.

The results of the present study were meant to confirm one of the hypotheses and deny the other.

\section{Materials and Methods}

A retrospective study was conducted on a sample of dental casts and CBCT scans of 60 patients with MTD from two orthodontic offices (two cities Cluj Napoca and Satu Mare) randomly selected by adopting a convenience and a cluster sampling method and in accordance with the following inclusion criteria: 1 . no orthodontic treatment before; 2. acceptable quality CBCT images with clearly identifiable structures of the maxilla and mandible (see Appendix A for further details regarding CBCT characteristics); 3. goodquality dental casts without any deterioration that could hinder the measurements; 4 . dental cast and CBCT image obtained in the same week.

The exclusion criteria were the absence of the reference teeth: upper incisors, first upper premolar and first permanent molars, macro- or microdontia, and presence of deciduous teeth.

A total of 158 subjects were excluded from an initial number of 218 cases considered for the present study. Frequent criteria for exclusions were the dental compensation, absence of reference teeth (upper lateral incisors, 1st maxillary and mandibular molars, and maxillary premolars), deficient records (absent casts or CBCT scans), and treatment already started at the time of performing the CBCT scans.

For each patient, the transverse dimension of the maxilla was assessed by a single trained investigator supervised by the authors responsible for this role, both on dental cast using PI with a digital caliper with sharp beaks and on CBCT images by the UPCBCT analysis with Planmeca Romexis Viewer 6.0.1.812 software. The results were calculated after measurements were taken for both tests, and the thresholds for classifying the results were pre-specified.

To calculate the ideal value of PI for a particular patient, the sum of the mesiodistal diameter of the four upper incisors (SI) was first measured (Figure 1a). Secondly, the ideal inter-premolar distance (IP) and the ideal inter-molar distance (IM) were calculated using the following formulae [16]:

Ideal IP $=$ SI $\times 100 / 80$ (premolar arch width)

Ideal IM $=$ SI $\times 100 / 64$ (molar arch width)

The real premolar and molar arch width were measured with the digital caliper by placing the beaks in the center of the occlusal groove of the first maxillary premolars and the center of the occlusal surface of the first permanent molars (Figure 1b). The measured value is subtracted from the calculated value to assess the presence of a maxillary deficiency. If the measured values are smaller than the calculated ones, then a narrowing of the maxilla is indicated by PI at the level of the premolars or molars. A $2 \mathrm{~mm}$ difference between the calculated and measured values is allowed. A mild maxillary narrowing is diagnosed when the difference is between 2 and $4 \mathrm{~mm}$. When the difference is between 4 and $6 \mathrm{~mm}$, a medium narrowing is present. A severe narrowing occurs when the difference is between 6 and $10 \mathrm{~mm}$, while a very severe narrowing is present when the difference is more than $10 \mathrm{~mm}$. As mentioned before in the introduction, Pont's Index has some drawbacks that may induce errors in results interpretation. The buccal inclination of the posterior teeth determines a higher value for real IP and IM that masks a true skeletal MTD. Also, the abnormal variations of mesiodistal size of the incisors, as hypoplastic lateral incisor or Bolton discrepancy, can modify the value of SI and the ideal value of IP and IM, which leads to a false interpretation of the results. 


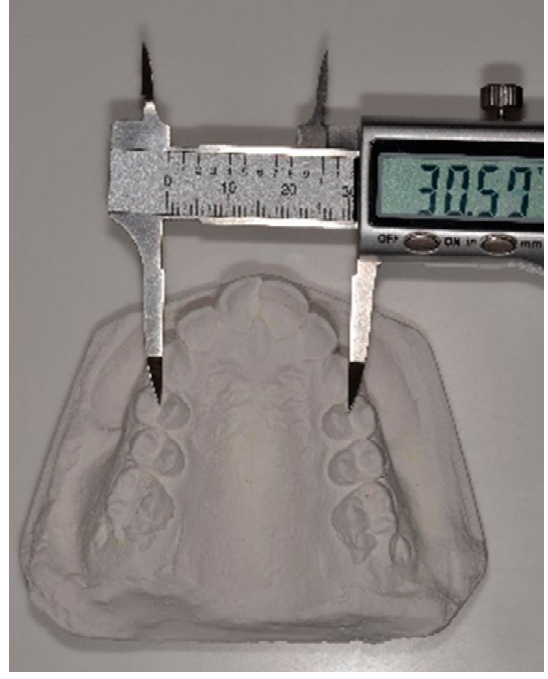

(a)

Legend: measurement for real SI and real IP

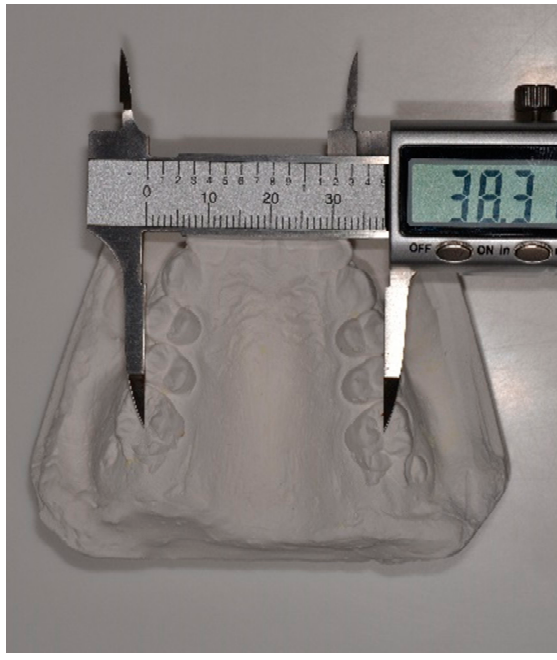

(b)

Legend: measurement of real IM

Figure 1. Methods of measuring: (a) SI and IP with the digital caliper by placing the beaks in the center of the occlusal groove of the first maxillary premolars; (b) IM in the center of the occlusal surface of the first permanent molars.

For calculating the ideal value of UPCBCT analysis, the Mx-Mx (Figure 2) and the WALA-WALA (Figure 2) distances were measured on the CBCT scans. To calculate the difference in width between the maxilla and the mandible, the mandibular width was subtracted from the maxillary width then the measured difference was subtracted from 5 to determine the amount of expansion needed, expressed in millimeters [1,17].

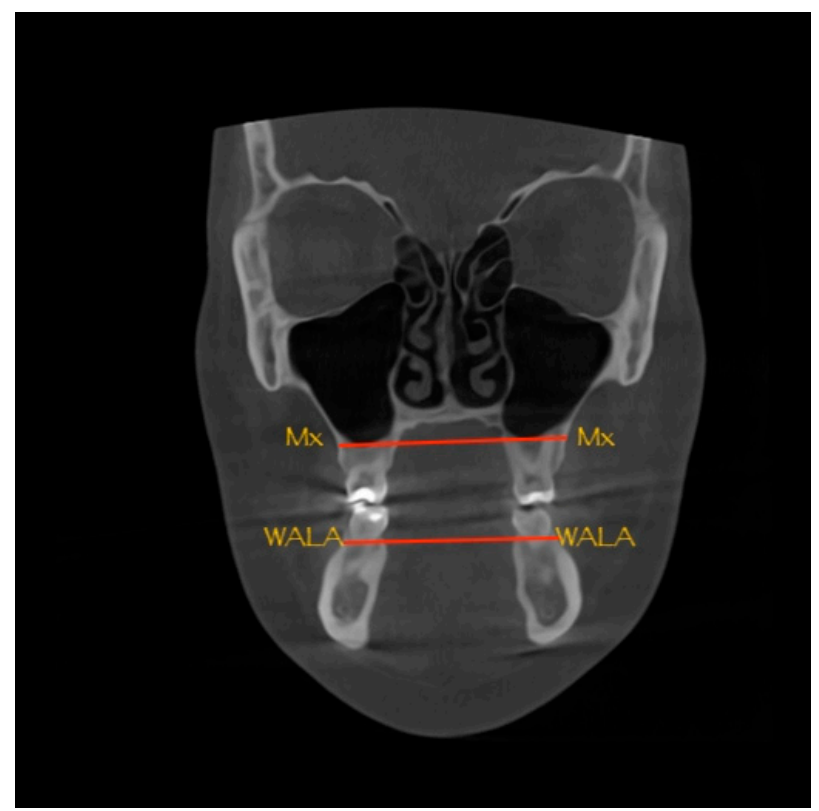

Figure 2. UPCBCT analysis: Mx-Mx and WALA-WALA distances.

\section{Statistical Analysis}

The results were analyzed using McNemar's test computed using appropriate functions on Excel Data Analysis version 16.16.27 (201012) and the accuracy indicators calculated using the online version of (c) 2022 MedCalc Software Ltd. [18]. As both tests were performed on the same series of subjects (matched groups), thus obtaining paired data, 
McNemar's test was the best choice to correlate the test results of PI and the presence or absence of MTD as indicated by the results of UPCBCT analysis. In order to reject the null hypothesis $\left(H_{0}\right)$, differences were considered statistically significant if the $p$-value was less than 0.05 [19].

To quantify the link between the test results of PI and the presence or absence of MTD, several diagnostic accuracy indicators needed to be computed. A contingency table based on a pivot table was used to calculate: sensitivity (Se), specificity (Sp), accuracy, positive likelihood ratio $(+\mathrm{LR})$, negative likelihood ratio $(-\mathrm{LR})$, positive predictive value (PPV), and negative predictive value (NPV) [20-22].

\section{Results}

A total number of 218 patients were considered for the study, from which 158 were eliminated, leaving a final total of 60 patients for the present study. The exclusion rate was $72.5 \%$. Of the target sample, $30.27 \%$ were eliminated due to dental compensation and missing reference teeth (upper lateral incisors, 1st maxillary and mandibular molars, and maxillary premolars), $20.64 \%$ were eliminated due to incomplete records, and a further $9.17 \%$ were eliminated due to having started the orthodontic treatment before the initial CBCT was taken or having macro-, microdontia. The preliminary power was 0.8 .

Table 1 depicts the results of the measurements of the transverse dimension of the maxilla in the current study's participants. The column "Results match" indicates whether the results of the two diagnostic methods match. An " $\mathrm{N}$ " indicates results that do not match. A " $Y$ " indicates that both UPCBCT analysis and PI indicate a narrow maxilla. A matching result occurred in three cases:

- When UPCBCT analysis indicates MTD and PI indicates MTD in the premolar region (IP); - When UPCBCT analysis indicates MTD and PI indicates MTD in the molar region (IM);

- When UPCBCT analysis indicates MTD and PI indicates MTD both in the premolar (IP) and molar (IM) regions.

In contrast to UPCBCT analysis, PI can have four test result types (TP, FP, TN, FN) as depicted in the last column of Table 1, which are the basis for computing the accuracy indicators. A summary of the four diagnostic types was included in the contingency table (Table 2). Table 3 summarizes the resulted values of the accuracy indicators.

Table 1. Comparative evaluation of a transverse maxillary deficiency using the two methods: PI and UPCBCT analysis.

\begin{tabular}{|c|c|c|c|c|c|}
\hline \multirow[b]{2}{*}{ Case Number } & \multicolumn{2}{|c|}{ Pont's Index } & \multirow[b]{2}{*}{$\begin{array}{l}\text { UPCBCT Results } \\
(\mathrm{mm})\end{array}$} & \multirow[b]{2}{*}{$\begin{array}{l}\text { Results Match * } \\
\text { YES(Y)/NO(N) }\end{array}$} & \multirow[b]{2}{*}{ TP/FP/TN/FN ** } \\
\hline & $\begin{array}{l}\text { Calculated- } \\
\text { Measured IP } \\
(\mathrm{mm})\end{array}$ & $\begin{array}{l}\text { Calculated- } \\
\text { Measured IM } \\
(\mathrm{mm})\end{array}$ & & & \\
\hline 1 & -1.9 & 1.75 & -3.4 & Y & $\mathrm{TN}$ \\
\hline 2 & 2.9875 & 2.599375 & 0.19 & Y & $\mathrm{TP}$ \\
\hline 3 & 2.2175 & 1.296875 & -2.2 & $\mathrm{~N}$ & FP \\
\hline 4 & 1.58 & 6.93 & 1 & $\mathrm{Y}$ & $\mathrm{TP}$ \\
\hline 5 & 5.8875 & 4.391875 & 4 & $\mathrm{Y}$ & $\mathrm{TP}$ \\
\hline 6 & 3.85 & 4.8175 & 0.2 & $\mathrm{Y}$ & $\mathrm{TP}$ \\
\hline 7 & 3.5025 & 7.698125 & 3.8 & $\mathrm{Y}$ & $\mathrm{TP}$ \\
\hline 8 & 2.63 & 1.2375 & -3 & $\mathrm{~N}$ & FP \\
\hline 9 & 4.085 & 6.20625 & 2.19 & $\mathrm{Y}$ & $\mathrm{TP}$ \\
\hline 10 & 8.3675 & 8.674375 & 2.6 & $\mathrm{Y}$ & $\mathrm{TP}$ \\
\hline 11 & 5.45 & 4.6225 & 2.4 & $\mathrm{Y}$ & $\mathrm{TP}$ \\
\hline 12 & 2.99 & 2.485 & 1.8 & $\mathrm{Y}$ & $\mathrm{TP}$ \\
\hline 13 & -2.63 & 4.84 & -2.2 & $\mathrm{~N}$ & $\mathrm{FP}$ \\
\hline 14 & 4.925 & 9.93375 & 5.4 & $\mathrm{Y}$ & $\mathrm{TP}$ \\
\hline 15 & 4.8475 & 5.339375 & -4.6 & $\mathrm{~N}$ & FP \\
\hline
\end{tabular}


Table 1. Cont.

\begin{tabular}{|c|c|c|c|c|c|}
\hline \multirow[b]{2}{*}{ Case Number } & \multicolumn{2}{|c|}{ Pont's Index } & \multirow[b]{2}{*}{$\begin{array}{l}\text { UPCBCT Results } \\
(\mathrm{mm})\end{array}$} & \multirow[b]{2}{*}{$\begin{array}{l}\text { Results Match * } \\
\text { YES(Y)/NO(N) }\end{array}$} & \multirow[b]{2}{*}{$\mathrm{TP} / \mathrm{FP} / \mathrm{TN} / \mathrm{FN} * *$} \\
\hline & $\begin{array}{l}\text { Calculated- } \\
\text { Measured IP } \\
(\mathrm{mm})\end{array}$ & $\begin{array}{l}\text { Calculated- } \\
\text { Measured IM } \\
(\mathrm{mm})\end{array}$ & & & \\
\hline 16 & 1.995 & 4.43375 & -0.19 & $\mathrm{~N}$ & FP \\
\hline 17 & 3.375 & 6.12625 & -3.8 & $\mathrm{~N}$ & FP \\
\hline 18 & -1.825 & 0.72375 & 0.8 & $\mathrm{~N}$ & FN \\
\hline 19 & 2.78 & 0.6125 & 1.8 & $\mathrm{Y}$ & $\mathrm{TP}$ \\
\hline 20 & 2.9325 & 3.050625 & 0.2 & $\mathrm{Y}$ & $\mathrm{TP}$ \\
\hline 21 & 3.9025 & 4.083125 & 3.8 & Y & $\mathrm{TP}$ \\
\hline 22 & -0.82 & -1.56 & -1 & $\mathrm{Y}$ & $\mathrm{TN}$ \\
\hline 23 & 2.6375 & 2.046875 & 5.4 & $\mathrm{Y}$ & $\mathrm{TP}$ \\
\hline 24 & -1.0325 & -2.725625 & 12 & $\mathrm{~N}$ & FN \\
\hline 25 & 3.7125 & 3.270625 & 3.8 & $\mathrm{Y}$ & $\mathrm{TP}$ \\
\hline 26 & 2.1725 & -0.814375 & 5.1 & $\mathrm{Y}$ & $\mathrm{TP}$ \\
\hline 27 & 1.62 & 0.6625 & -0.6 & Y & $\mathrm{TN}$ \\
\hline 28 & 8.1825 & 12.930625 & 2.6 & Y & $\mathrm{TP}$ \\
\hline 29 & 4.7325 & 3.115625 & 5.4 & $\mathrm{Y}$ & $\mathrm{TP}$ \\
\hline 30 & 2.175 & 0.36125 & -0.3 & $\mathrm{~N}$ & $\mathrm{FP}$ \\
\hline 31 & 6.82 & 5.5125 & 4.6 & $\mathrm{Y}$ & $\mathrm{TP}$ \\
\hline 32 & 5.965 & 7.65875 & -1 & $\mathrm{~N}$ & $\mathrm{FP}$ \\
\hline 33 & 7.4 & 4.15 & 5 & $\mathrm{Y}$ & $\mathrm{TP}$ \\
\hline 34 & 3.3875 & 3.984375 & 1.2 & $\mathrm{Y}$ & $\mathrm{TP}$ \\
\hline 35 & -2.115 & -3.85375 & 4.6 & $\mathrm{~N}$ & FN \\
\hline 36 & -1.275 & -3.07375 & 5 & $\mathrm{~N}$ & FN \\
\hline 37 & 0.165 & -7.59125 & 12.6 & $\mathrm{~N}$ & FN \\
\hline 38 & 1.5275 & 4.664375 & -2 & $\mathrm{~N}$ & $\mathrm{FP}$ \\
\hline 39 & 0.7275 & 0.421875 & 3 & $\mathrm{~N}$ & FN \\
\hline 40 & 5.2 & 6 & 1.18 & $\mathrm{Y}$ & $\mathrm{TP}$ \\
\hline 41 & -2.855 & -2.35125 & 2.6 & $\mathrm{~N}$ & FN \\
\hline 42 & 0.1625 & -2.113125 & 6.6 & $\mathrm{~N}$ & FN \\
\hline 43 & 1.3025 & -1.206875 & 1.11 & $\mathrm{~N}$ & FN \\
\hline 44 & 2.6625 & 3.528125 & 1.01 & Y & $\mathrm{TP}$ \\
\hline 45 & 4.9025 & 8.370625 & -0.2 & $\mathrm{~N}$ & $\mathrm{FP}$ \\
\hline 46 & 3.2375 & 4.546875 & 3.37 & Y & $\mathrm{TP}$ \\
\hline 47 & 3.79 & 3.8925 & -1.8 & $\mathrm{~N}$ & $\mathrm{FP}$ \\
\hline 48 & 0.2925 & 3.190625 & -3 & $\mathrm{~N}$ & FP \\
\hline 49 & 3.2375 & 8.636875 & -0.19 & $\mathrm{~N}$ & $\mathrm{FP}$ \\
\hline 50 & -0.1725 & -3.213125 & 5.8 & $\mathrm{~N}$ & FN \\
\hline 51 & 4.875 & 6.42375 & 1.04 & $\mathrm{Y}$ & $\mathrm{TP}$ \\
\hline 52 & 0.2375 & -1.103125 & 1 & $\mathrm{~N}$ & FN \\
\hline 53 & -2.97 & -4.3175 & 1.4 & $\mathrm{~N}$ & FN \\
\hline 54 & 4.025 & 0.58375 & -2.2 & $\mathrm{~N}$ & $\mathrm{FP}$ \\
\hline 55 & 2.7 & 3.565 & 5.8 & $\mathrm{Y}$ & $\mathrm{TP}$ \\
\hline 56 & 0.64 & 5.3125 & -1.8 & $\mathrm{~N}$ & $\mathrm{FP}$ \\
\hline 57 & 2.495 & 2.80875 & 7.4 & $\mathrm{Y}$ & $\mathrm{TP}$ \\
\hline 58 & 2.155 & -0.08125 & 4.6 & $\mathrm{Y}$ & $\mathrm{TP}$ \\
\hline 59 & 1.46 & 2.105 & 1 & $\mathrm{Y}$ & $\mathrm{TP}$ \\
\hline 60 & 1.2875 & 1.199375 & 8.2 & $\mathrm{~N}$ & FN \\
\hline
\end{tabular}

Legend: * A matching result occurred in three cases: when UPCBCT analysis indicates MTD and PI indicates MTD in the premolar region (IP); when UPCBCT analysis indicates MTD and PI indicates MTD in the molar region (IM); when UPCBCT analysis indicates MTD and PI indicates MTD both in the premolar (IP) and molar (IM) regions. ${ }^{* *}$ TP: true positive; FP: false positive; TN: true negative; FN: false negative. 
Table 2. Test results of Pont's analysis compared to the reference standard Penn CBCT.

\begin{tabular}{cccc}
\hline $\begin{array}{c}\text { Pont's Analysis Compared } \\
\text { to Penn CBCT }\end{array}$ & Gold Standard & \\
\hline Diagnostic test & CBCT Positive & CBCT Negative & Total \\
\hline Pont Positive & $\begin{array}{c}\text { True positive } \\
29\end{array}$ & $\begin{array}{c}\text { False positive } \\
15\end{array}$ & 44 \\
\hline \multirow{2}{*}{ Pont Negative } & False negative & True negative & \multirow{2}{*}{16} \\
\hline Total & 13 & 18 & 60 \\
\hline
\end{tabular}

Table 3. Summary of the accuracy indicators of Pont's analysis based on the contingency table (Table 2).

\begin{tabular}{ccc}
\hline Accuracy Indicator & Value & $\begin{array}{c}\text { Upper and Lower Limits } \\
\text { (Confidence Interval: 95\%) }\end{array}$ \\
\hline Sensitivity & $69 \%$ & $52.91-82.38 \%$ \\
\hline Specificity & $16.6 \%$ & $3.58-41.42 \%$ \\
\hline PPV & $65 \%$ & $59.14-72.08 \%$ \\
\hline NPV & $18.75 \%$ & $6.95-41.61 \%$ \\
\hline LR+ & 0.83 & $0.62-1.11 \%$ \\
\hline LR- & 1.86 & $0.6-5.73 \%$ \\
\hline Accuracy & $53.28 \%$ & $40-66.33 \%$
\end{tabular}

Legend: PPV: positive predictive value; NPV: negative predictive value; LR+: positive likelihood ratio; LR-: negative likelihood ratio.

In order to refute or accept the null hypothesis, McNemar's test was computed using functions in an excel sheet (Table 4).

Table 4. McNemar's test.

\begin{tabular}{cccc}
\hline Case Number & Pont's Index & Penn CBCT & Pretest-Posttest \\
\hline 1 & 0 & 0 & 0 \\
2 & 1 & 1 & 0 \\
3 & 1 & 0 & 1 \\
4 & 1 & 1 & 0 \\
5 & 1 & 1 & 0 \\
6 & 1 & 1 & 0 \\
7 & 1 & 1 & 0 \\
8 & 1 & 0 & 1 \\
9 & 1 & 1 & 0 \\
10 & 1 & 1 & 0 \\
11 & 1 & 1 & 0 \\
12 & 1 & 1 & 0 \\
13 & 1 & 0 & 1 \\
14 & 1 & 1 & 0 \\
15 & 1 & 0 & 1 \\
16 & 1 & 0 & 1 \\
17 & 1 & 0 & 1 \\
18 & 0 & 1 & -1 \\
19 & 1 & 1 & 0 \\
20 & 1 & 1 & 0 \\
\hline
\end{tabular}


Table 4. Cont.

\begin{tabular}{|c|c|c|c|}
\hline Case Number & Pont's Index & Penn CBCT & Pretest-Posttest \\
\hline 21 & 1 & 1 & 0 \\
\hline 22 & 0 & 0 & 0 \\
\hline 23 & 1 & 1 & 0 \\
\hline 24 & 0 & 1 & -1 \\
\hline 25 & 1 & 1 & 0 \\
\hline 26 & 1 & 1 & 0 \\
\hline 27 & 0 & 0 & 0 \\
\hline 28 & 1 & 1 & 0 \\
\hline 29 & 1 & 1 & 0 \\
\hline 30 & 1 & 0 & 1 \\
\hline 31 & 1 & 1 & 0 \\
\hline 32 & 1 & 0 & 1 \\
\hline 33 & 1 & 1 & 0 \\
\hline 34 & 1 & 1 & 0 \\
\hline 35 & 0 & 1 & -1 \\
\hline 36 & 0 & 1 & -1 \\
\hline 37 & 0 & 1 & -1 \\
\hline 38 & 1 & 0 & 1 \\
\hline 39 & 0 & 1 & -1 \\
\hline 40 & 1 & 1 & 0 \\
\hline 41 & 0 & 1 & -1 \\
\hline 42 & 0 & 1 & -1 \\
\hline 43 & 0 & 1 & -1 \\
\hline 44 & 1 & 1 & 0 \\
\hline 45 & 1 & 0 & 1 \\
\hline 46 & 1 & 1 & 0 \\
\hline 47 & 1 & 0 & 1 \\
\hline 48 & 1 & 0 & 1 \\
\hline 49 & 1 & 0 & 1 \\
\hline 50 & 0 & 1 & -1 \\
\hline 51 & 1 & 1 & 0 \\
\hline 52 & 0 & 1 & -1 \\
\hline 53 & 0 & 1 & -1 \\
\hline 54 & 1 & 0 & 1 \\
\hline 55 & 1 & 1 & 0 \\
\hline 56 & 1 & 0 & 1 \\
\hline 57 & 1 & 1 & 0 \\
\hline 58 & 1 & 1 & 0 \\
\hline 59 & 1 & 1 & 0 \\
\hline 60 & 0 & 1 & -1 \\
\hline
\end{tabular}

Legend: $0=$ negative test result; $1=$ positive test result; false positive $(1 \rightarrow 0)=15$; false negative $(0 \rightarrow 1)=13$; Chi-square (test statistic) $=0.035714286 ; p$-value $=0.850106739 \rightarrow p>0.05$ not statistically significant

\section{Discussions}

The disadvantages of UPCBCT analysis resulting from the CBCT technology lead to the need for a preliminary risk-benefit analysis (especially in children) and for an assessment of the accuracy of alternative diagnostic methods (PI) [4].

Comparisons were made between the results of the two diagnostic methods for MTD, PI, and UPCBCT analysis. The statistical test used to assess the difference between the two diagnostic methods was the McNemar's test, together with accuracy indicators. McNemar's test revealed a $p$-value of 0.85 , indicating that the differences between the results of the two methods are not statistically significant, which could be explained by an insufficient number of tested subjects. Therefore, the null hypothesis $H_{0}$ of the current study has to be accepted.

Furthermore, a sensitivity of $69 \%$ indicates a probability of 0.69 for a patient with a maxillary transverse deficiency to test positively using PI. A specificity of $16.6 \%$ may indicate a probability of 0.166 for a patient without a maxillary deficiency to test negatively 
using PI. These are only estimates for sensitivity and specificity as they are based on a subset of subjects from the target population; if a different subset of subjects was tested or the same subjects was tested at different times, the estimates of sensitivity and specificity would be numerically different $[20,22,23]$.

Cases of MTD in children or when the midpalatal suture is still active can be treated with numerous appliances [24]; a diagnostic test with high sensitivity is required to treat subjects with narrow maxilla. The UPCBCT analysis would be suitable as it represents the current gold standard [11,12]; however, due to its risk of radiation, another diagnostic test with higher sensitivity should be considered. The present study found that in comparison with the UPCBCT analysis, PI has a sensitivity of $69 \%$, making it suitable for diagnosing a transverse maxillary deficiency in minors [20].

On the other hand, the treatment of MTD in adults, where the midpalatal suture is closed, might require micro-implants-assisted rapid palatal expansion or surgically assisted rapid maxillary expansion, suggesting the need for a diagnostic test with high specificity to avoid treating patients who do not have a narrow maxilla $[20,25]$. In these situations, diagnosis with the UPCBCT analysis is justified despite the risk of ionizing radiation [20].

A PPV of $65.9 \%$ indicates a probability of 0.659 for subjects who tested positive with PI to have MTD, whereas an NPV of $18.75 \%$ indicates a probability of 0.1875 for subjects who tested negative with PI to not have MTD. The increased percentage of the PPV and the relatively low percentage of the NPV can be explained by the high estimated prevalence of MTD, equaling 70\% among the target population in the present study. The higher the prevalence of the disease (MTD), the more the certainty of a positive test result indicating the presence of the disease increases, thus having a high PPV. Inversely, the lower the prevalence, the more the certainty of a negative test result indicating the absence of MTD increases, meaning a high NPV. Therefore, PPV and NPV estimates within the present study cannot be applied to other populations without knowing the prevalence of MTD in those populations $[20,22]$.

The LR indicates to which extent a positive or negative test result can change the likelihood that a subject has the disease. The $+\mathrm{LR}$ of PI is +0.83 , indicating a 1 -fold increase in the odds of having MTD in a patient with a positive result. The higher the $+\mathrm{LR}$, the more informative PI is. On the other hand, a +LR of 1.0 means that PI is useless as the odds of having MTD has not changed after the PI (a 1-fold increase in the odds means the odds have not changed). Nevertheless, the $-\mathrm{LR}$ for PI is +1.86 , indicating a 2 -fold decrease in the odds of having MTD in a patient with a negative result. The smaller the $-\mathrm{LR}$, the more informative the test. The use of a diagnostic test is based on the importance of ruling in or ruling out the disease, since an +LR greater than 10 or an -LR lower than 0.1 provide convincing diagnostic evidence. However, single studies are usually less informative regarding LRs than high-quality systematic reviews, indicating the inclusion of the present study in systematic reviews together with other similar studies and the need for further research [26].

The accuracy of the PI as compared to the UPCBCT analysis in the current study was $53.28 \%$, meaning that the PI has 53.28\% correct results among all the test results [27].

The key inclusion and exclusion criteria, along with the materials and methods, were clearly described, leading to the replicability of the present study, thus increasing its external validity. The diagnostic tests can be reproduced by trained personnel, and it further depends on the availability of $\mathrm{CBCT}$ technology in the area. Although in the present study, comparisons were made between the CBCT scans of one patient and the dental cast of the same patient, CBCT characteristics were provided in Appendix A. The relevance of the CBCT characteristics within the context of the present study's design could be the subject of further research.

Over- or under- interpretation of the reference standard was avoided by calculating the results only after all measurements were taken for both diagnostic tests and after prespecified threshold values were used to classify the results. The present study was based on 
the guiding principles of the STARD 2015 statement (STAndards for Reporting Diagnostic accuracy studies) [28].

A cluster sampling method was used to select subjects for the present study, the sample being representative of the population, as there were equal chances for people to choose one or the other of the two orthodontic office (Cluj-Napoca and Satu Mare, two Romanian localities). By adopting a cluster sampling method, a random inclusion of various degrees of MTD was achieved, leading to the generalizability of the findings to the target population [28].

Bias could arise from the fact that there was a single trained examiner, leading to low inter-examiner reliability. Moreover, as the measurements were not performed two times with a specific time difference, the intra-examiner reliability could be one of the study's limitations [28].

The present study is innovative as no other study compares the UPCBCT analysis to PI. Even though the current study did not find a statistically significant difference between PI and UPCBCT analysis $(p>0.05)$, the literature review by Kathiravan concluded that PI cannot be used to predict maxillary arch width reliably [15]. A further disadvantage of PI is that the measurements can be negatively affected by dental compensation (buccolingual inclination) leading to underdiagnosis of skeletal maxillary constriction. Nevertheless, Agnihotri and Gulati support the use of PI as they found in their recent study a definite correlation between the width of the arch and the width of the four maxillary incisors within the Northern Indian population [29].

\section{Conclusions}

Within the limitations of the present study and based on its results, the following conclusions can be summarized:

1. There was no statistically significant difference between the two diagnostic methods as the null hypothesis was accepted.

2. Since CBCT is not a daily used investigation and PI has a relatively high sensitivity (69\%), PI is suitable to detect MTD. However, assessment of MTD on CBCT can be recommended for cases where the midpalatal suture maturation should also be evaluated.

Author Contributions: Conceptualization, D.F.; methodology, D.F.; software, E.B.N.; validation, E.B.N.; formal analysis, M.H.; investigation, M.G.; resources, E.B.N.; data curation, A.M.E.; writingoriginal draft preparation, E.B.N.; writing—review and editing, A.M.E.; visualization, M.G.; supervision, M.H. and A.M.E.; project administration, D.F. All authors contributed equally. All authors have read and agreed to the published version of the manuscript.

Funding: This research received no external funding.

Institutional Review Board Statement: Ethical review and approval were waived for this study as the research just used measurements performed on dental casts and CBCT scans, not involving clinical activities on patients.

Informed Consent Statement: Informed consent was obtained from all subjects involved in the study.

Data Availability Statement: The data presented in this study are available on request from the corresponding author.

Acknowledgments: We thank Rednik Deutschlander Beatrix Marianna for providing dental casts, CBCT scans and for useful discussions. We thank Deacu Liviu for useful discussions.

Conflicts of Interest: The authors declare no conflict of interest. 


\section{Appendix A}

Table A1. Summary of the CBCT characteristics.

\begin{tabular}{|c|c|}
\hline Ca se Number & CBCT I mAge Quality Infor mAtion \\
\hline 1 & $\varnothing 20.2 \times 20.2 \mathrm{~cm}(504 \times 504 \times 504) 400 \mu \mathrm{m} 90 \mathrm{KV} 12 \mathrm{~mA} 4.678 \mathrm{~s}$ \\
\hline 2 & $\varnothing 20.3 \times 20.3 \mathrm{~cm}(507 \times 507 \times 507) 400 \mu \mathrm{m} 90 \mathrm{KV} 12 \mathrm{~mA} 13.746 \mathrm{~s}$ \\
\hline 3 & Ø20.2 × $20.2 \mathrm{~cm}(504 \times 504 \times 504) 400 \mu \mathrm{m} 88 \mathrm{KV} 11 \mathrm{~mA} 4.716 \mathrm{~s}$ \\
\hline 4 & $\varnothing 20.1 \times 20.1 \mathrm{~cm}(503 \times 503 \times 503) 400 \mu \mathrm{m} 85 \mathrm{KV} 8 \mathrm{~mA} 4.73 \mathrm{~s}$ \\
\hline 5 & $\varnothing 20.0 \times 20.0 \mathrm{~cm}(501 \times 501 \times 501) 400 \mu \mathrm{m} 90 \mathrm{KV} 12 \mathrm{~mA} 13.857 \mathrm{~s}$ \\
\hline 6 & $\varnothing 20.1 \times 20.1 \mathrm{~cm}(503 \times 503 \times 503) 400 \mu \mathrm{m} 84 \mathrm{KV} 10 \mathrm{~mA} 13.764 \mathrm{~s}$ \\
\hline 7 & Ø20.1 × $20.1 \mathrm{~cm}(502 \times 502 \times 502) 400 \mu \mathrm{m} 88 \mathrm{KV} 6 \mathrm{~mA} 4.701 \mathrm{~s}$ \\
\hline 8 & $\varnothing 20.0 \times 20.0 \mathrm{~cm}(500 \times 500 \times 500) 400 \mu \mathrm{m} 87 \mathrm{KV} 12 \mathrm{~mA} 4.675 \mathrm{~s}$ \\
\hline 9 & $\varnothing 20.1 \times 20.1 \mathrm{~cm}(502 \times 502 \times 502) 400 \mu \mathrm{m} 88 \mathrm{KV} 10 \mathrm{~mA} 4.747 \mathrm{~s}$ \\
\hline 10 & $\varnothing 20.1 \times 20.1 \mathrm{~cm}(502 \times 502 \times 502) 400 \mu \mathrm{m} 90 \mathrm{KV} 8 \mathrm{~mA} 13.865 \mathrm{~s}$ \\
\hline 11 & $\varnothing 20.2 \times 20.2 \mathrm{~cm}(504 \times 504 \times 504) 400 \mu \mathrm{m} 88 \mathrm{KV} 11 \mathrm{~mA} 4.72 \mathrm{~s}$ \\
\hline 12 & $\varnothing 10.0 \times 10.0 \mathrm{~cm}(250 \times 250 \times 250) 400 \mu \mathrm{m} 90 \mathrm{KV} 7 \mathrm{~mA} 4.074 \mathrm{~s} 256.0 \mathrm{mGyxcm}{ }^{2}$ \\
\hline 13 & $\varnothing 20.0 \times 20.0 \mathrm{~cm}(500 \times 500 \times 500) 400 \mu \mathrm{m} 82 \mathrm{KV} 8 \mathrm{~mA} 13.55 \mathrm{~s}$ \\
\hline 14 & $\varnothing 20.2 \times 20.2 \mathrm{~cm}(504 \times 504 \times 504) 400 \mu \mathrm{m} 88 \mathrm{KV} 9 \mathrm{~mA} 13.8 \mathrm{~s}$ \\
\hline 15 & $\varnothing 20.1 \times 20.1 \mathrm{~cm}(502 \times 502 \times 502) 400 \mu \mathrm{m} 86 \mathrm{KV} 8 \mathrm{~mA} 4.5 \mathrm{~s}$ \\
\hline 16 & $\varnothing 16.0 \times 16.0 \mathrm{~cm}(800 \times 800 \times 800) 200 \mu \mathrm{m} 99 \mathrm{KV} 8 \mathrm{~mA} 9.0 \mathrm{~s} 1610.0 \mathrm{mGyxcm}^{2}$ \\
\hline 17 & $\varnothing 20.2 \times 20.2 \mathrm{~cm}(504 \times 504 \times 504) 400 \mu \mathrm{m} 86 \mathrm{KV} 11 \mathrm{~mA} 4.691 \mathrm{~s}$ \\
\hline 18 & $\varnothing 20.1 \times 20.1 \mathrm{~cm}(502 \times 502 \times 502) 400 \mu \mathrm{m} 89 \mathrm{KV} 11 \mathrm{~mA} 13.435 \mathrm{~s}$ \\
\hline 19 & $\varnothing 20.0 \times 20.0 \mathrm{~cm}(501 \times 501 \times 501) 400 \mu \mathrm{m} 80 \mathrm{KV} 11 \mathrm{~mA} 4.699 \mathrm{~s}$ \\
\hline 20 & $\varnothing 20.2 \times 20.2 \mathrm{~cm}(504 \times 504 \times 504) 400 \mu \mathrm{m} 88 \mathrm{KV} 11 \mathrm{~mA} 4.72 \mathrm{~s}$ \\
\hline 21 & $\varnothing 20.1 \times 20.1 \mathrm{~cm}(503 \times 503 \times 503) 400 \mu \mathrm{m} 84 \mathrm{KV} 9 \mathrm{~mA} 6.4 \mathrm{~s}$ \\
\hline 22 & $\varnothing 20.1 \times 20.1 \mathrm{~cm}(502 \times 502 \times 502) 400 \mu \mathrm{m} 90 \mathrm{KV} 10 \mathrm{~mA} 4.875 \mathrm{~s}$ \\
\hline 23 & $\varnothing 20.0 \times 20.0 \mathrm{~cm}(500 \times 500 \times 500) 400 \mu \mathrm{m} 85 \mathrm{KV} 11 \mathrm{~mA} 4.575 \mathrm{~s}$ \\
\hline 24 & $\varnothing 20.2 \times 20.2 \mathrm{~cm}(504 \times 504 \times 504) 400 \mu \mathrm{m} 90 \mathrm{KV} 10 \mathrm{~mA} 11.8 \mathrm{~s}$ \\
\hline 25 & $\varnothing 20.1 \times 20.1 \mathrm{~cm}(503 \times 503 \times 503) 400 \mu \mathrm{m} 85 \mathrm{KV} 10 \mathrm{~mA} 7.4 \mathrm{~s}$ \\
\hline 26 & Ø20.1 × $20.1 \mathrm{~cm}(502 \times 502 \times 502) 400 \mu \mathrm{m} 88 \mathrm{KV} 11 \mathrm{~mA} 13.747 \mathrm{~s}$ \\
\hline 27 & $\varnothing 20.3 \times 20.3 \mathrm{~cm}(507 \times 507 \times 507) 400 \mu \mathrm{m} 90 \mathrm{KV} 12 \mathrm{~mA} 12.646 \mathrm{~s}$ \\
\hline 28 & Ø20.1 × $20.1 \mathrm{~cm}(502 \times 502 \times 502) 400 \mu \mathrm{m} 88 \mathrm{KV} 7 \mathrm{~mA} 5.701 \mathrm{~s}$ \\
\hline 29 & $\varnothing 20.0 \times 20.0 \mathrm{~cm}(500 \times 500 \times 500) 400 \mu \mathrm{m} 88 \mathrm{KV} 9 \mathrm{~mA} 13.675 \mathrm{~s}$ \\
\hline 30 & $\varnothing 20.0 \times 20.0 \mathrm{~cm}(501 \times 501 \times 501) 400 \mu \mathrm{m} 89 \mathrm{KV} 11 \mathrm{~mA} 9.457 \mathrm{~s}$ \\
\hline 31 & $\varnothing 20.1 \times 20.1 \mathrm{~cm}(502 \times 502 \times 502) 400 \mu \mathrm{m} 87 \mathrm{KV} 8 \mathrm{~mA} 9.701 \mathrm{~s}$ \\
\hline 32 & $\varnothing 20.2 \times 20.2 \mathrm{~cm}(504 \times 504 \times 504) 400 \mu \mathrm{m} 87 \mathrm{KV} 10 \mathrm{~mA} 9.8 \mathrm{~s}$ \\
\hline 33 & $\varnothing 20.0 \times 20.0 \mathrm{~cm}(501 \times 501 \times 501) 400 \mu \mathrm{m} 87 \mathrm{KV} 9 \mathrm{~mA} 8.457 \mathrm{~s}$ \\
\hline 34 & $\varnothing 20.1 \times 20.1 \mathrm{~cm}(503 \times 503 \times 503) 400 \mu \mathrm{m} 88 \mathrm{KV} 11 \mathrm{~mA} 9.4 \mathrm{~s}$ \\
\hline 35 & $\varnothing 20.1 \times 20.1 \mathrm{~cm}(502 \times 502 \times 502) 400 \mu \mathrm{m} 87 \mathrm{KV} 9 \mathrm{~mA} 4.8476 \mathrm{~s}$ \\
\hline 36 & $\varnothing 20.3 \times 20.3 \mathrm{~cm}(507 \times 507 \times 507) 400 \mu \mathrm{m} 90 \mathrm{KV} 12 \mathrm{~mA} 11.896 \mathrm{~s}$ \\
\hline 37 & $\varnothing 20.2 \times 20.2 \mathrm{~cm}(504 \times 504 \times 504) 400 \mu \mathrm{m} 88 \mathrm{KV} 10 \mathrm{~mA} 7.886 \mathrm{~s}$ \\
\hline 38 & $\varnothing 20.1 \times 20.1 \mathrm{~cm}(502 \times 502 \times 502) 400 \mu \mathrm{m} 89 \mathrm{KV} 9 \mathrm{~mA} 7.788 \mathrm{~s}$ \\
\hline 39 & $\varnothing 20.0 \times 20.0 \mathrm{~cm}(500 \times 500 \times 500) 400 \mu \mathrm{m} 90 \mathrm{KV} 11 \mathrm{~mA} 4.745 \mathrm{~s}$ \\
\hline 40 & $\varnothing 20.0 \times 20.0 \mathrm{~cm}(501 \times 501 \times 501) 400 \mu \mathrm{m} 88 \mathrm{KV} 10 \mathrm{~mA} 7.885 \mathrm{~s}$ \\
\hline 41 & Ø20.1 × $20.1 \mathrm{~cm}(503 \times 503 \times 503) 400 \mu \mathrm{m} 86 \mathrm{KV} 9 \mathrm{~mA} 9.55 \mathrm{~s}$ \\
\hline 42 & $\varnothing 20.1 \times 20.1 \mathrm{~cm}(502 \times 502 \times 502) 400 \mu \mathrm{m} 87 \mathrm{KV} 8 \mathrm{~mA} 5.767 \mathrm{~s}$ \\
\hline 43 & Ø20.2 × $20.2 \mathrm{~cm}(504 \times 504 \times 504) 400 \mu \mathrm{m} 87 \mathrm{KV} 9 \mathrm{~mA} 6.89 \mathrm{~s}$ \\
\hline 44 & $\varnothing 20.1 \times 20.1 \mathrm{~cm}(502 \times 502 \times 502) 400 \mu \mathrm{m} 88 \mathrm{KV} 11 \mathrm{~mA} 13.47 \mathrm{~s}$ \\
\hline 45 & Ø20.1 × $20.1 \mathrm{~cm}(502 \times 502 \times 502) 400 \mu \mathrm{m} 90 \mathrm{KV} 10 \mathrm{~mA} 8.387 \mathrm{~s}$ \\
\hline 46 & $\varnothing 20.0 \times 20.0 \mathrm{~cm}(501 \times 501 \times 501) 400 \mu \mathrm{m} 89 \mathrm{KV} 12 \mathrm{~mA} 13.765 \mathrm{~s}$ \\
\hline 47 & $\varnothing 20.0 \times 20.0 \mathrm{~cm}(501 \times 501 \times 501) 400 \mu \mathrm{m} 90 \mathrm{KV} 11 \mathrm{~mA} 4.885 \mathrm{~s}$ \\
\hline 48 & $\varnothing 20.1 \times 20.1 \mathrm{~cm}(503 \times 503 \times 503) 400 \mu \mathrm{m} 85 \mathrm{KV} 10 \mathrm{~mA} 7.4 \mathrm{~s}$ \\
\hline 49 & Ø20.1 × $20.1 \mathrm{~cm}(502 \times 502 \times 502) 400 \mu \mathrm{m} 90 \mathrm{KV} 9 \mathrm{~mA} 8.797 \mathrm{~s}$ \\
\hline 50 & $\varnothing 20.1 \times 20.1 \mathrm{~cm}(502 \times 502 \times 502) 400 \mu \mathrm{m} 90 \mathrm{KV} 10 \mathrm{~mA} 6.747 \mathrm{~s}$ \\
\hline 51 & $\varnothing 20.1 \times 20.1 \mathrm{~cm}(502 \times 502 \times 502) 400 \mu \mathrm{m} 88 \mathrm{KV} 10 \mathrm{~mA} 4.887 \mathrm{~s}$ \\
\hline 52 & $\varnothing 20.1 \times 20.1 \mathrm{~cm}(503 \times 503 \times 503) 400 \mu \mathrm{m} 84 \mathrm{KV} 10 \mathrm{~mA} 5.34 \mathrm{~s}$ \\
\hline 53 & $\varnothing 10.0 \times 10.0 \mathrm{~cm}(250 \times 250 \times 250) 400 \mu \mathrm{m} 89 \mathrm{KV} 8 \mathrm{~mA} 5.066 \mathrm{~s}$ \\
\hline 54 & $\varnothing 20.0 \times 20.0 \mathrm{~cm}(500 \times 500 \times 500) 400 \mu \mathrm{m} 87 \mathrm{KV} 9 \mathrm{~mA} 4.545 \mathrm{~s}$ \\
\hline 55 & $\varnothing 20.3 \times 20.3 \mathrm{~cm}(507 \times 507 \times 507) 400 \mu \mathrm{m} 90 \mathrm{KV} 11 \mathrm{~mA} 10.556 \mathrm{~s}$ \\
\hline 56 & $\varnothing 20.1 \times 20.1 \mathrm{~cm}(502 \times 502 \times 502) 400 \mu \mathrm{m} 87 \mathrm{KV} 6 \mathrm{~mA} 4.134 \mathrm{~s}$ \\
\hline 57 & $\varnothing 20.2 \times 20.2 \mathrm{~cm}(504 \times 504 \times 504) 400 \mu \mathrm{m} 88 \mathrm{KV} 9 \mathrm{~mA} 12.876 \mathrm{~s}$ \\
\hline 58 & $\varnothing 20.0 \times 20.0 \mathrm{~cm}(501 \times 501 \times 501) 400 \mu \mathrm{m} 90 \mathrm{KV} 12 \mathrm{~mA} 12.757 \mathrm{~s}$ \\
\hline 59 & Ø20.1 × $20.1 \mathrm{~cm}(502 \times 502 \times 502) 400 \mu \mathrm{m} 88 \mathrm{KV} 11 \mathrm{~mA} 8.767 \mathrm{~s}$ \\
\hline 60 & $\varnothing 20.1 \times 20.1 \mathrm{~cm}(502 \times 502 \times 502) 400 \mu \mathrm{m} 87 \mathrm{KV} 8 \mathrm{~mA} 6.877 \mathrm{~s}$ \\
\hline
\end{tabular}




\section{References}

1. Tamburrino, R.K.; Boucher, N.S.; Vanarsdall, R.L.; Secchi, A. The Transverse Dimension: Diagnosis and Relevance to Functional Occlusion. Roth Williams Int. Soc. Orthod. J. 2010, 2, 13-22.

2. Sawchuka, D.; Curriea, K.; Vich, M.L.; Palomob, J.M.; Flores-Mira, C. Diagnostic methods for assessing maxillary skeletal and dental transverse deficiencies: A systematic review. Korean J. Orthod. 2016, 46, 331-342. [CrossRef] [PubMed]

3. Festila, D.; Enache, M.; Ghergie, L.M. Treatment modalities of skeletal maxillary deficiency: A review. Rom. J. Stomatol. 2018, 64, 172-178. [CrossRef]

4. Kapila, S.D.; Nervina, J.M. CBCT in orthodontics: Assessment of treatment outcomes and indications for its use. Dentomaxillofacial Radiol. 2015, 44, 20140282. [CrossRef] [PubMed]

5. Proffit, W.R.; Fields, H.W.; Larson, B.E.; Sarver, D.M. Contemporary Orthodontics; Elsevier Inc.: Philadelphia, PA, USA, 2019.

6. Andrucioli, M.C.D.; Matsumoto, M.A.N. Transverse maxillary deficiency: Treatment alternatives in face of early skeletal maturation. Dent. Press J. Orthod. 2020, 25, 70-79. [CrossRef] [PubMed]

7. Joondeph, D.R.; Riedel, R.A.; Moore, A.W. Pont's index: A clinical evaluation. Angle Orthod. 1970, 40, 112-118. [CrossRef] [PubMed]

8. McNamara, J.A. Maxillary transverse deficiency. Am. J. Orthod. Dentofac. Orthop. 2000, 117, 567-570. [CrossRef] [PubMed]

9. Betts, N.J.; Vanarsdall, R.L.; Barber, H.D.; Higgins-Barber, K.; Fonseca, R.J. Diagnosis and treatment of transverse maxillary deficiency. Int. J. Adult Orthod. Orthognath. Surg. 1995, 10, 75-96. [PubMed]

10. Leonardi, R.; Lo Giudice, A.; Rugeri, M.; Muraglie, S.; Cordasco, G.; Barbato, E. Three-dimensional evaluation on digital casts of maxillary palatal size and morphology in patients with functional posterior crossbite. Eur. J. Orthod. 2018, 40, 556-562. [CrossRef] [PubMed]

11. González, A.G.; López, A.F.; Fernández, S.T.; Ocampo, A.M.; Valencia, J.E. Sensitivity and specificity of a radiographic, tomographic and digital model analysis for determining transverse discrepancies. Rev. Mex. De Ortod. 2018, 6, $26-32$.

12. Hayes, J. The etiology of malocclusion and the "scientific method". Orthod. Pract. 2020, 11, 62-65.

13. Giudice, A.L.; Ronsivalle, V.; Lagravere, M.; Leonardi, R.; Martina, S.; Isola, G. Transverse dentoalveolar response of mandibular arch after rapid maxillary expansion (RME) with tooth-borne and bone-borne appliances. Angle Orthod. 2020, 90, 680-687. [CrossRef] [PubMed]

14. Baysal, A.; Veli, I.; Ucar, F.I.; Eruz, M.; Ozer, T.; Uysal, T. Changes in mandibular transversal arch dimensions after rapid maxillary expansion procedure assessed through cone-beam computed tomography. Korean J. Orthod. Korean Assoc. Orthod. 2011, 41, 200-210. [CrossRef]

15. Kathiravan, P.; Khurshead, A.M.; Wei, C.N. Pont's Index Is Not Exact Science: A Reappraisal. Int. Med. J. $2013,20,204-207$.

16. Terrez, Y.C.; Fitzmaurice, O.S.; Tejada, H.E.P. Pont's index in study models of patients who finished a non-extraction orthodontic treatment at the Orthodontic Clinic of the Postgraduate Studies and Research Division of the National University of Mexico. Rev. Mex. De Ortod. 2013, 1, e7-e12. [CrossRef]

17. Tamburrino, R.K. Complete Clinical Orthodontics®Orthodontic Treatment Design. Available online: https://www. raffaelespenaortodonzia.it/public/files/page_79/cco-treatment\%20design\%202018.pdf (accessed on 19 November 2021).

18. Free Statistical Calculators. MedCalc. Available online: https://www.medcalc.org/calc/diagnostic_test.php (accessed on 19 November 2021).

19. Bowers, D. Medical Statistics from Scratch: An Introduction for Health Professionals, 2nd ed.; John Wiley \& Sons Ltd.: West Sussex, UK, 2008; ISBN 978-047-051-301-9.

20. Hazra, A.; Gogtay, N. Biostatistics series module 7: The statistics of diagnostic tests. Indian J. Dermatol. 2017, 62, 18-24. [CrossRef] [PubMed]

21. Campbell, M.J.; Freeman, J.V. The University of Sheffield. Available online: https://www.sheffield.ac.uk/polopoly_fs/1.43990! / file/Tutorial-13-diagnostic-tests.pdf (accessed on 19 November 2021).

22. Mandrekar, J.N. Simple Statistical Measures for Diagnostic Accuracy Assessment. J. Thorac. Oncol. 2010, 5, 763-764. [CrossRef] [PubMed]

23. Meier, K.U.S. Department of Health and Human Services Food and Drug Administration Center for Devices and Radiological Health. Available online: https:/ / www.fda.gov/regulatory-information/search-fda-guidance-documents/statistical-guidancereporting-results-studies-evaluating-diagnostic-tests-guidance-industry-and-fda (accessed on 19 November 2021).

24. Agarwal, A.; Mathur, R. Maxillary Expansion. Int. J. Clin. Pediatric Dent. 2010, 3, 139-146. [CrossRef] [PubMed]

25. Angelieri, F.; Cevidanes, L.H.; Franchi, L.; Gonçalves, R.; Benavides, E.; McNamara, J.A., Jr. Midpalatal suture maturation: Classification method for individual assessment before rapid maxillary expansion. Am. J. Orthod. Dentofac. Orthop. 2013, 144, 759-769. [CrossRef]

26. Centre for Reviews and Dissemination, University of York. Available online: https://www.york.ac.uk/media/crd/Systematic_ Reviews.pdf (accessed on 19 November 2021).

27. Wenge, Z.; Zeng, N.F.; Wang, N. Sensitivity, Specificity, Accuracy, Associated Confidence Interval and ROC Analysis with Practical SAS Implementations. Health Care Life Sci. 2010, 19, 67. 
28. Bossuyt, P.M.; Reitsma, J.B.; Bruns, D.E.; Gatsonis, C.A.; Glasziou, P.P.; Irwig, L.; Lijmer, J.G.; Moher, D.; Rennie, D.; de Vet, H.C.; et al. STARD 2015: An Updated List of Essential Items for Reporting Diagnostic Accuracy Studies. Radiology 2015, $277,826-832$. [CrossRef] [PubMed]

29. Agnihotri, G.; Gulati, M. Maxillary molar and premolar indices in North Indians. Internet J. Biol. Anthropol. 2008, 2, 1-5. 